\title{
Simulator with integrated HW and SW for prediction of thermal comfort to provide feedback to the climate control system
}

\author{
Jan Pokorný1, ${ }^{1,}$, Barbora Kopečková ${ }^{1}$, Jan Fišer $^{1}$ and Miroslav Jícha ${ }^{1}$ \\ ${ }^{1}$ Brno University of Technology, Faculty of Mechanical Engineering, Energy Institute, Technická 2896/2, Brno, Czech Republic
}

\begin{abstract}
The aim of the paper is to assemble a simulator for evaluation of thermal comfort in car cabins in order to give a feedback to the HVAC (heating, ventilation and air conditioning) system. The HW (hardware) part of simulator is formed by thermal manikin Newton and RH (relative humidity), velocity and temperature probes. The SW (software) part consists of the Thermal Comfort Analyser (using ISO 14505-2) and Virtual Testing Stand of Car Cabin defining the heat loads of car cabin. Simulator can provide recommendation for the climate control how to improve thermal comfort in cabin by distribution and directing of air flow, and also by amount of ventilation power to keep optimal temperature inside a cabin. The methods of evaluation of thermal comfort were verified by tests with 10 test subjects for summer (summer clothing, ambient air temperature $30{ }^{\circ} \mathrm{C}, \mathrm{HVAC}$ setup: $+24{ }^{\circ} \mathrm{C}$ auto) and winter conditions (winter clothing, ambient air temperature $-5{ }^{\circ} \mathrm{C}, \mathrm{HVAC}$ setup: $+18{ }^{\circ} \mathrm{C}$ auto). The tests confirmed the validity of the thermal comfort evaluation using the thermal manikin and ISO 14505-2.
\end{abstract}

\section{Introduction}

The issue of thermal comfort in cars is still relevant especially in the context of energy savings. To achieve thermal comfort with less energy demands is possible by improving the used materials (glazing, car painting, etc.) HVAC (heating, ventilation and air conditioning) technologies and also car climate control systems.

This paper refers to assembly a simulator with integrated hardware (thermal manikin Newton with probes) and software (TCA, VTSCC) for prediction of thermal comfort to provide feedback to the climate control system.

The main feature of simulator is evaluation of effect of clothing on thermal comfort using thermal manikin [1] or at least sensors of equivalent temperature [2]. Both work on the principle of EHT (equivalent homogenous temperature) and comfort zones [3]. The advantage of thermal manikin compared to the sensors of EHT is that it follows the shape of the human body, that influences the air flow around the measured point and also the heated surfaces generate similar plumes as real human. Thermal manikins can be used to evaluate new strategies of cabin ventilation, which is currently widely studied, not only for electric vehicles, where air-conditioning (A/C) system can significantly impact their performance, but also for self-driving vehicles, etc.

The related question is how much energy will be needed to obtain optimal conditions. To answer this question, the car cabin heat load models can be used as a simple pre-developmental design tool. In this context, several car cabins and HVAC models have been developed up to now. Kiss [4] developed automotive
$\mathrm{A} / \mathrm{C}$ system simulation tool on the MATLAB/Simulink platform. The model consists of a detailed cooling circuit model and relatively simple cabin model. In the study of Fayazbakhsh [5], a comprehensive heat balance model was developed for usage in mobile air-conditioning design. The model takes the vehicle geometry, material properties, and driving conditions characteristics as input. Macros [6] proposed a thermal model of a vehicle cabin. The model was verified by considering the cabin of a real car outfitted with a temperature sensor network. Torregrosa-Jaime [7] developed a lumped-parameter thermal model of the passenger's compartment of a vehicle. This transient thermal model was also validated with experimental data under varies ambient conditions. In the study of Lee [8], the transient thermal model of the passenger car's cabin was developed to investigate the dynamic behaviour of cabin thermal conditions. Brèque [9] developed a transient mono-zonal thermal model of a vehicle cabin in order to predict the thermal needs. The model considered conduction, convection, radiation heat transfers as well as the HVAC and moisture air impacts.

The aim of this work is to verify these methods and demonstrate that the simulator is able to help evaluate climate control efficiency.

\section{Methods}

As mentioned above, the simulator consists of hardware and software part. The hardware part is formed by thermal manikin Newton and additional probes of air velocity, RH, and temperature sensors. The software part consists of TCA (Thermal Comfort Analyzer) [10] and

\footnotetext{
* Corresponding author: pokorny.j@.fme.vutbr.cz
} 
VTSCC (Virtual Testing Stand of Car Cabin) [11, 12]. TCA is empirical based model that evaluates thermal comfort by using Newton manikin and comfort zones method [3]. VTSCC is heat balance model able to predict temperatures and heat loads of the car cabin based on real operational data. Both software models were developed in Matlab and compiled into the executable applications.

The first step was to verify comfort zones method against human subject's tests by using thermal manikin and TCA (chapter 2.1 and 2.2). When this method was verified, the comfort zones were used to evaluate local thermal comfort to provide recommendations for distribution and directing of air flow to the human surface in order to improve thermal comfort.

The second step was to apply VTSCC to calculate car cabin heat loads to provide recommendation how to change the HVAC power (feeding air temperature and total mass flow) to improve thermal comfort inside a car cabin (chapter 2.3).

\subsection{Thermal manikin and Comfort zones}

Thermal manikin (Figure 1) is the human body shape device for measuring heat fluxes from its surface for given temperatures. In this study, we prefer this method to evaluate EHT. The second method is to keep constant heat fluxes and monitor the surface temperatures. EHT is defined as temperature of a uniform space, in which all surface temperatures are equal to air temperature, there is no air movement other than the self-convection of the manikin and the rate of heat loss would be the same as was actually measured. EHT is useful as a basis for comparison for complex and highly non-uniform thermal environment, such as automobiles [13].

The diagram of comfort zones (Figure 3 and 8) imagines the subjects' votes of larger group of people to 18 body parts. The black line in these diagrams represents the objective measurement of EHT, more specifically heat losses from thermal manikin body when is tempered on $34{ }^{\circ} \mathrm{C}$. Based on the positon of the line in the diagram the local thermal sensation/comfort can be evaluated and thus the recommendation to climate control can be done.

Comfort zones are defined by the range of EHT which is associated with the range of mean thermal vote (MTV). MTV uses the 7-point Bedford scale comfort, the diagram has 5 zones and only 3 zones represent comfort, outside these comfort zones it is discomfort anyway, see Table 1.

Table. 1 MTV scale and comfort zones

\begin{tabular}{|c|c|c|}
\hline MTV & Scale & Comfort zones \\
\cline { 1 - 2 }+3 & Much too hot & \multirow{2}{*}{ MTV $>1.5$} \\
\hline+2 & Too hot & \\
\cline { 1 - 2 }+1 & Hot but comfortable & MTV $>0.5$ \\
\hline 0 & Neutral & $-0.5<\mathrm{MTV}<0.5$ \\
\hline-1 & Cold but comfortable & MTV $<-0.5$ \\
\hline-2 & Too cold & \multirow{2}{*}{$\mathrm{MTV}<-1.5$} \\
\hline-3 & Much too cold & \\
\hline
\end{tabular}

The diagram shape i.e. range of specific comfort zone depends on the clothing (more insulation means wider zones and higher tolerance to lower EHT). To identify shape of the diagram the calibration for the specific clothing ensemble is necessary.

In this paper, the calibration data of indoor summer and winter are used. These data were measured separately before the own tests with human subjects in climate chamber. For summer clothing, the total insulation was 1.13 clo and for winter clothing 1.46 clo. The intrinsic insulation was 0.49 clo (summer) and 0.82 clo (winter), where $1 \mathrm{clo}=0.155 \mathrm{~m}^{2} \mathrm{~K} / \mathrm{W}$.

We applied these "clo" values to diagram and evaluated thermal comfort by the comfort zones method and thermal manikin Newton. It provides together with inherited probes of $\mathrm{RH}$, velocity and temperatures information about local heat fluxes and cabin environment (e.g. temperatures at the feet and head level of manikin T1_Feet, T2_Head). TCA calculated from these heat fluxes Newton's local EHTs and MTVs (see black line in comfort zones diagrams) and also diagrams of comfort zones were plotted in the Figure 3 and 8.

\subsection{Climate chamber tests with human subjects}

The aim of the test procedure was to answer the question: "Does the manikin report the same thermal comfort as the test subject?" To be able to compare results of thermal manikin Newton and test subjects, they had to be exposure to the same well defined environmental conditions. For this reason, the experiment was carried out in the climate chamber (NETME centre, Brno), where a test car was prepared for the experiment. Thermal manikin was sitting on the co-driver's seat, while test subject was sitting on the driver's place.
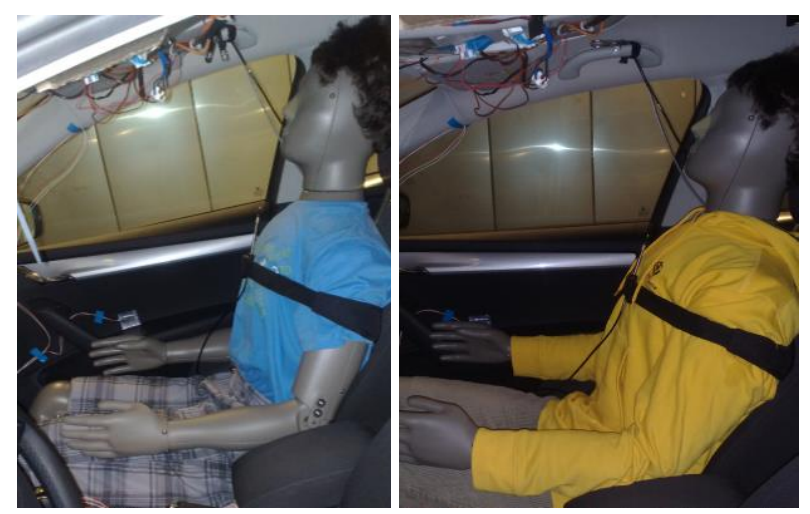

Fig. 1. Thermal manikin with summer and winter clothing.

The test procedure included summer and winter driving conditions. We investigated a group of 10 people (young males 23-35 years old) for both conditions, altogether we collected 20 questionnaires. We were able to measure four volunteers (test subjects) per day, and the whole experimental procedure took six days. The time schedule of typical test day was analogical to test day 1 with test subjects N.1-4.

The test car was parked into the climate chamber and preconditioned for at least two hours in given conditions, 
including switching off thermal manikin that was dressed in summer/winter clothing (Figure 1).

Then the HVAC was setup to expected comfort level (summer: $+24{ }^{\circ} \mathrm{C}$ auto, winter: $+18{ }^{\circ} \mathrm{C}$ auto) and the cabin environment was preconditioned for next 30 minutes. Meanwhile test subjects were stabilized in the control room outside the climate chamber.

The first test subject N.1 entered the cabin with the supervisor of the experiment. Thus, two people were in the cabin during filling questionnaires and one thermal manikin. The questionnaires were filled immediately after they got into the car, and then after 20 and 30 minutes.

When subject N.1 ended procedure the HVAC was still in operation and no people were inside for $30 \mathrm{~min}$ to obtain similar starting environmental condition for the second test subject N.2.

After the subject N.2, there was at least one hour break for the lunch. The HVAC system was off during this period and thus the temperature in the cabin was influenced only by conditions in the climate chamber. In the afternoon, tests were performed with subjects N.3 and N.4.

During the test procedure, the conditions in climate chamber were monitored (temperature, humidity, solar intensity). Also, the test car was equipped by PT100 sensors to monitor temperature inside a car cabin, including feeding air form vents. The amount of feeding ventilation air was calculated from the voltage on fan terminals. In addition, some data from inbuilt sensors were possible to read using the CAN (Controller Area Network) of the car.

\subsection{Calculation of cabin heat loads}

The measured data of ambient environment and HVAC setup were used as input data to the VTSCC model. More specifically, following boundary conditions together with description of geometry and material compositions of car cabin define VTSSC input interface. $T \_A M B\left({ }^{\circ} \mathrm{C}\right)$ - ambient temperature outside the car was controlled by climate chamber: summer test $\sim 30-34{ }^{\circ} \mathrm{C}$, winter test $\sim-5^{\circ} \mathrm{C}(\sim$ means approximate value $)$.

T_VENT $\left({ }^{\circ} \mathrm{C}\right)$ - average temperature of feeding air measured in all opened vent (summer test $\sim 25{ }^{\circ} \mathrm{C}$, winter test $\sim 23^{\circ} \mathrm{C}$ ).

$U_{-} V E N T(\mathrm{~V})$ - for summer conditions the voltage was considered $3.7 \mathrm{~V}$ and for winter $4.3 \mathrm{~V}$. Volumetric flow rate of feeding air was then $143 \mathrm{~m}^{3} / \mathrm{h}$ and $169 \mathrm{~m}^{3} / \mathrm{h}$.

N_OCC (-) - number of occupants defines internal sources. In the simulation, the heating power of human was considered $100 \mathrm{~W}$ and the power of manikin was directly measured by himself and it was generally in range of 50-150 W (only at start of the test day manikin needed more power to heat up itself).

$T O P T\left({ }^{\circ} \mathrm{C}\right)$ - optimal EHT inside a car cabin. Defined by position of Wholebody neutral comfort zone $(\mathrm{MTV}=0)$. It is different for summer and winter clothing $\left(25.7^{\circ} \mathrm{C}\right.$ and $\left.23^{\circ} \mathrm{C}\right)$.

I SOL $\left(\mathrm{W} / \mathrm{m}^{2}\right)$ - during all tests solar intensity was zero. SPEED $(\mathrm{km} / \mathrm{h})$ - during all tests car was idling and the relative air speed was $\sim 5 \mathrm{~km} / \mathrm{h}$.
RH (\%) - the effect of relative humidity was not considered in this study, because the RH of feeding air was not measured (it was assumed $50 \%$ ).

These boundary conditions were used to calculate the air temperature inside a cabin $T_{-} I N\left({ }^{\circ} \mathrm{C}\right)$, and also the heat loads of cabin: from vents $Q_{-} V E N T(\mathrm{~W})$, by heat generation of all passengers including thermal manikin $Q M E T(\mathrm{~W})$, by conduction through cabin envelope Q_COND (W) and by radiation, especially solar radiation $Q \_S O L(\mathrm{~W})$. Also, the heat transfer by convection and radiation was considered to calculate temperatures inside the cabin.

The validity of heat loads calculation was proved by the comparison of predicted $T_{-} I N$ and measured air temperatures $\mathrm{T1}$ Feet and T2_Head (Figure 5 and 10). In addition, optimal ventilation power $Q_{-} V E N T \_O P T$ (W) was calculated to express the necessary power to reach optimal temperature $T \_O P T$. The difference between the actual $Q_{-} V E N T$ and optimal $Q_{-} V E N T \_O P T$, is then possible to use as recommendation for the change of the feeding air parameters such as temperature and volumetric flow rate.

\section{Results}

In this chapter, the results of human subject tests are presented for both conditions - summer and winter. We verified comfort zones method by average value of Wholebody MTV over all test subjects (N.1-10) in times after getting in car, after $20 \mathrm{~min}$ and after $30 \mathrm{~min}$. To demonstrate also evaluation of local thermal comfort, comfort zones diagram is plotted for the case: test subject N.2 after 30 min. Finally, the VTSCC prediction of cabin air temperature and cabin heat loads is demonstrated for test day with test subjects N.1-4.

\subsection{Summer conditions}

For the summer conditions the thermal manikin Newton and comfort zones evaluate thermal comfort very similar to human subjects at observed moments. The both approaches detect neutral sensation, tending to warm but comfortable. Figure 2 indicates that Newton's data best match the Global AVG data. It means that although the overall comfort can be evaluated from local thermal votes (Parts AVG), it is still more relevant to ask test subjects also for the overall comfort.

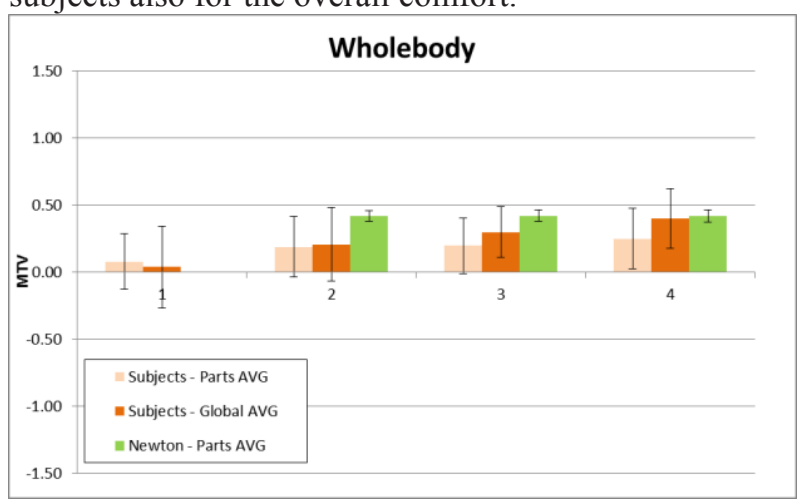

Fig. 2. Summer conditions evaluation of human subjects' tests - Wholebody MTV for all subjects N.1-10. 


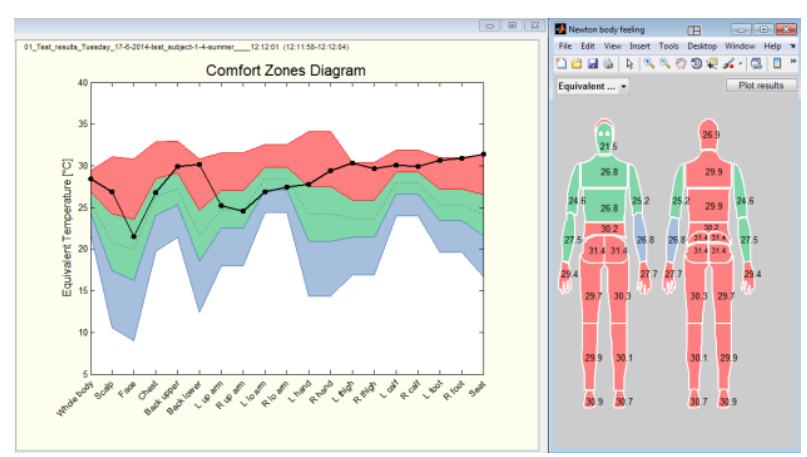

Fig. 3. Comfort zone diagram for summer; corresponding to the conditions of test subject N.2 after $30 \mathrm{~min}$.

A more detailed view on the conditions of test subject N.2 after 30 minutes (time 12:12) is shown in the Figure 3: Face, Chest, Arms were in neutral (except cold Left_Lower_Arm), whilst other parts were warm but comfortable. The average cabin air temperature was then $28.3{ }^{\circ} \mathrm{C}\left(\mathrm{T1}\right.$ Feet $=30.6{ }^{\circ} \mathrm{C}, \mathrm{T} 2$ Head $\left.=25.9^{\circ} \mathrm{C}\right)$, which was higher than the recommended EHT for optimal thermal comfort. Optimal EHT value for the summer clothing was determined based on the comfort zones diagram as $25.7^{\circ} \mathrm{C}$.

Mean radiant temperature does not differ significantly from cabin air temperatures. Because $T \_$Surf_AVG including interior temperatures such as dashboard, roof, floor, doors was in the range of air temperatures $T 1$ Feet and T2_Head. Only $T_{-}$Windshield representing glazing parts was a little bit higher, see Figure 5. This implies that in this case EHT can be estimated by cabin air temperatures (no solar radiation, low air speed around manikin).

Figure 4 shows specific boundary conditions such as ambient temperature inside a climate chamber, ventilation air temperature, the voltage of fan, which is proportional to the amount of feeding air, and also the heat generated by passengers including thermal manikin.

Figure 5 presents prediction of cabin mean air temperature $T \_I N$, which was mostly between measured air temperatures T1_Feet and T2_Head, measured by probes near Newton's feet and head. These results support the validity of VTSCC model, which was then used for calculation of car cabin heat loads (Figure 6).

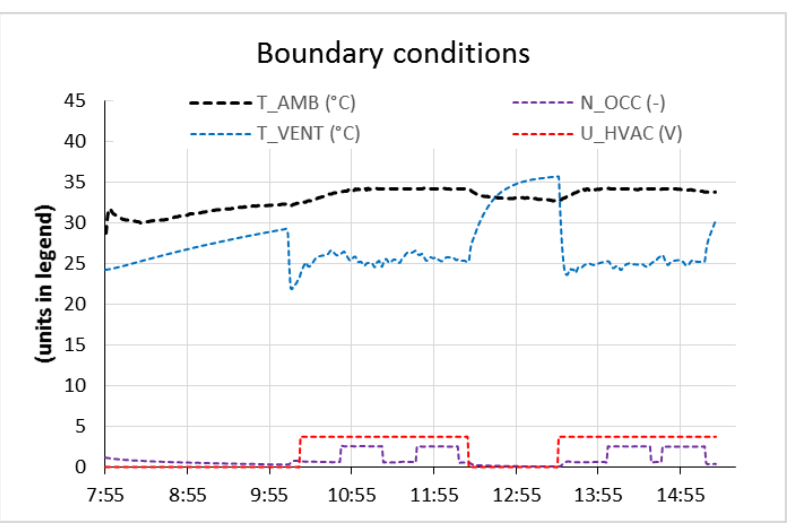

Fig. 4. Summer test for test subject. Boundary conditions.

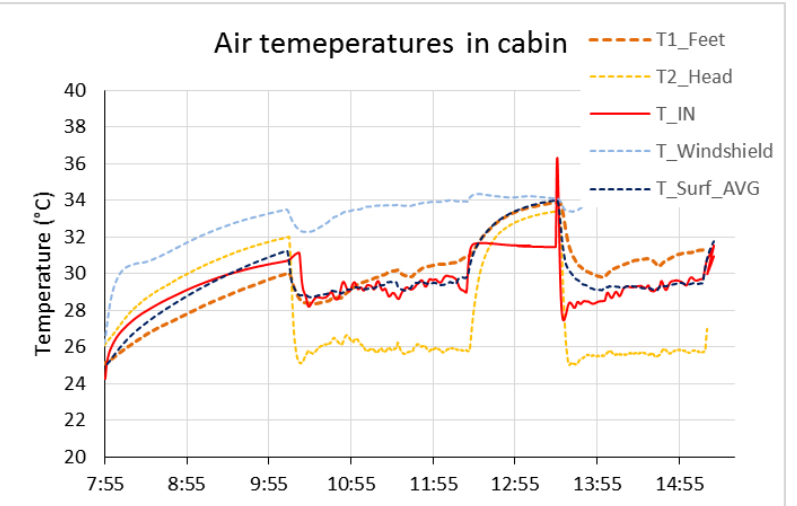

Fig. 5. Summer test for subject N.1-4. VTSCC prediction.

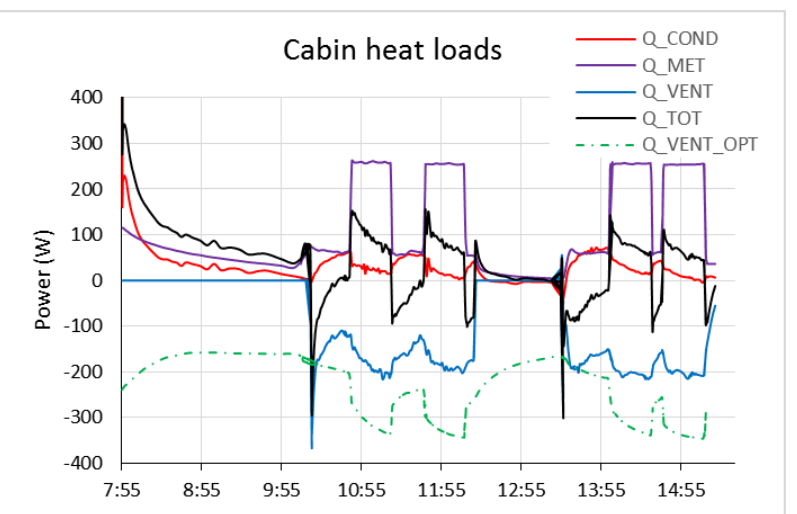

Fig. 6. Summer test for subject N.1-4. Cabin heat loads.

Q_MET was up to $250 \mathrm{~W}$ when there were people inside. $Q_{-} C O N D$ was below $50 \mathrm{~W}$ and tended to the $0 \mathrm{~W}$, when the inside air temperature approached to the outside temperature.

$Q_{-} T O T$ expresses a total heat load of car cabin, which is responsible for the change of temperature inside a cabin. The value was predominantly positive during the test, which implies slightly gradual increase of temperature inside a cabin. This was also observed during the test.

$Q_{-} V E N T$ was always higher when people were into the car because the automatic A/C system regulates the air temperature inside cabin.

Q_VENT_OPT was calculated for optimal cabin temperature $23{ }^{\circ} \mathrm{C}$. To achieve comfort level, it is recommended to cool down cabin by $\sim 300 \mathrm{~W}$ from vents instead of $\sim 200$ W. More details can be seen in Figure 6 as the difference between green dashed line and blue solid line.

These results can be used for the recommendation to the HVAC system, what should be changed. In this case, there is recommended to cool down lower parts of human body, and to achieve the optimal comfort it is recommended to cool down a feeding air by $\sim 100 \mathrm{~W}$.

\subsection{Winter conditions}

In the winter conditions, the thermal manikin Newton tends to be slightly more sensitive to cold than human (Figure 7). The thermal manikin detects already cold but comfortable, whilst the human subject refers just neutral state. But the difference is up to $\sim 0.5$ of MTV scale, which is the minimal distinction of the comfort scale (Table 1). As in summer case, Newton's data better 
match the experimental data considering also the global vote of test subjects, not only local votes.

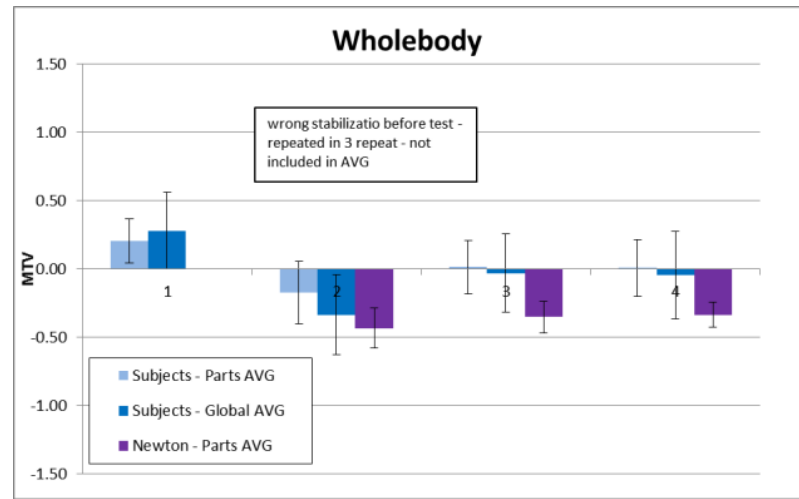

Fig. 7. Winter conditions evaluation of human subjects' tests Wholebody MTV for all subjects N.1-10.

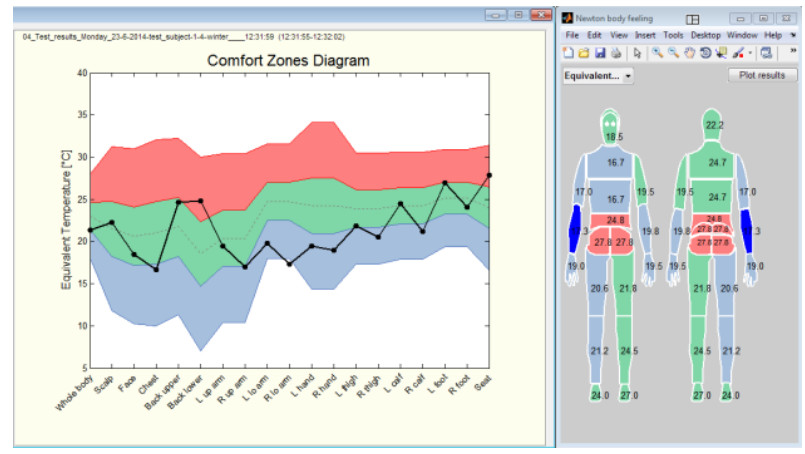

Fig. 8. Comfort zone diagram for winter; corresponding to the conditions of test subject N. 2 after $30 \mathrm{~min}$.

A more detailed view on the conditions of test subject N.2 after 30 minutes (time 12:32) is shown in the Figure 8: Scalp, Face, Back Upper, Left Upper Arm, Left Calf and Feet were in neutral, whilst other parts were cold but comfortable, or too cold (Right Lower Arm). Back Lower and Seat (Pelvis) were the only warm parts, because of their contact with the seat. The cabin air temperature was then $23.7^{\circ} \mathrm{C}\left(\right.$ T1 Feet $=23.2^{\circ} \mathrm{C}$, T2 Head $=24.2^{\circ} \mathrm{C}$ ), which was even higher than the optimal EHT. For the winter clothing it was determined as $23{ }^{\circ} \mathrm{C}$.

However, the mean radiant temperature differs from the air temperatures substantially, which is documented in the Figure 10. Interior surface temperature $T$ Surf_AVG including dashboard, roof, floor, doors was only $\sim 20{ }^{\circ} \mathrm{C}$ and $T$ Windshield was even below $10^{\circ} \mathrm{C}$. This implies mean radiant temperature MRT $\sim 18.3^{\circ} \mathrm{C}$ and EHT $\sim 21^{\circ} \mathrm{C}$, which explains why negative MTV was reported by manikin and human subjects even the air temperature was acceptable.

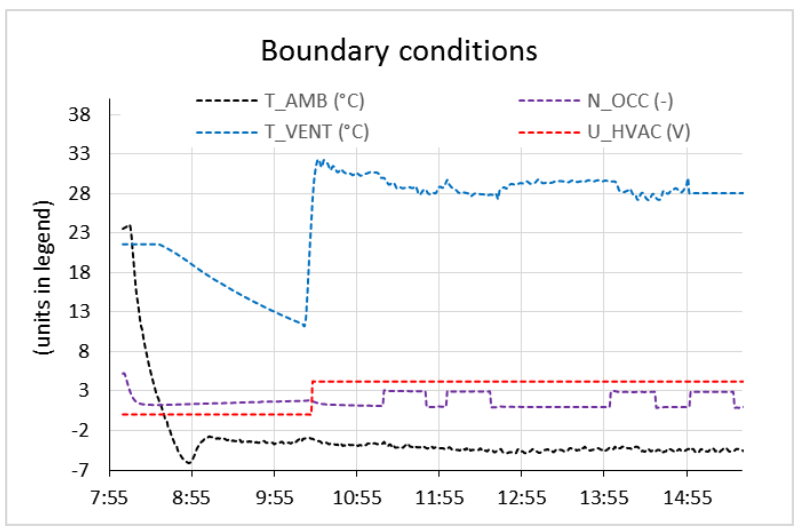

Fig. 9. Winter test for subject N.1-4. Boundary conditions.

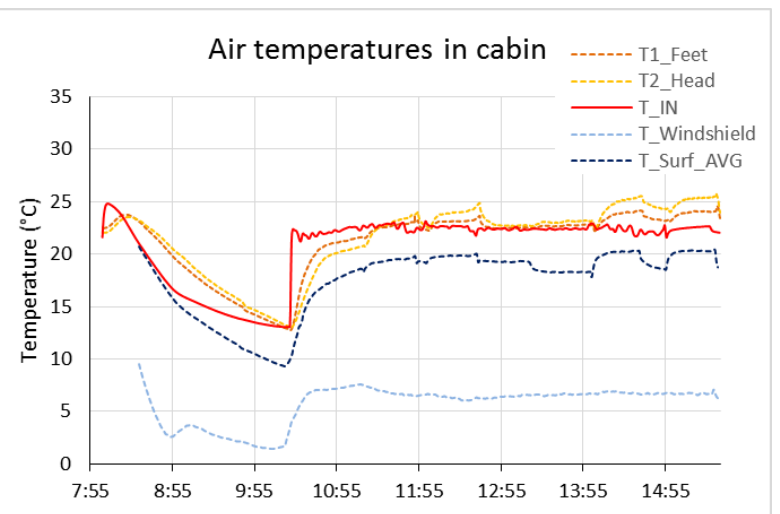

Fig. 10. Winter test for subject N.1-4. VSTCC prediction.

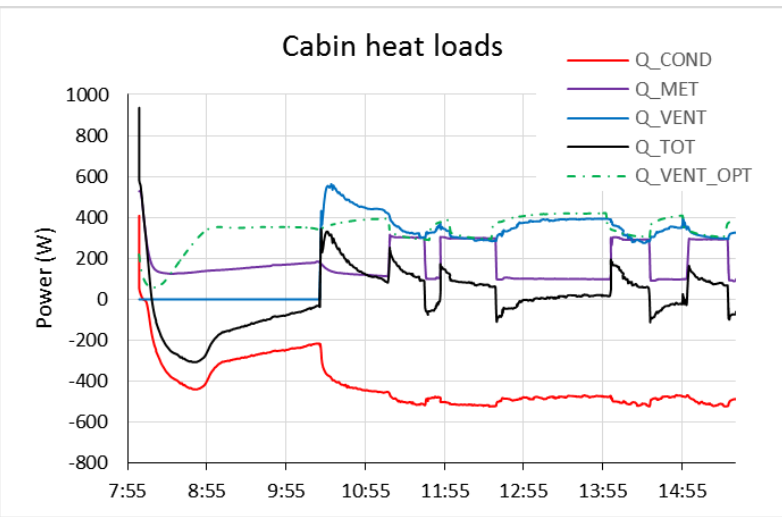

Fig. 11. Winter test for subjects N.1-4. Cabin heat loads.

Figure 9 shows specific boundary conditions of winter tests for test subjects N. 1-4. The predicted cabin air temperature $T_{-} I N$ was in accordance to the measured temperatures at the feet and head level (Figure 10). Calculated car cabin heat loads are then shown in the Figure 11.

Q_MET was up to $350 \mathrm{~W}$ except the start of preconditioning when the thermal manikin needed even more power to heat up itself.

$Q \_C O N D$ was below $-500 \mathrm{~W}$ during the climate control system keeping temperature on the optimal temperature. $Q_{-} T O T$ was positive just in case when test subjects were inside a car.

Q_VENT was $\sim 300 \mathrm{~W}$. Only at the beginning of the heating, before the subject N.1 entered into cabin, the ventilation heat load by feeding air was almost $600 \mathrm{~W}$. This illustrates why test subjects waited 30 minutes after 
HVAC was turned on: stabilization of conditions inside a cabin.

Q_VENT_OPT was also $\sim 300 \mathrm{~W}$ to achieve optimal cabin temperature $23{ }^{\circ} \mathrm{C}$ see green dotted line and solid blue in the Figure 11, when the test subjects were inside a cabin. In case, when test subjects were not inside and HVAC was on (e.g. 13:55) it rises to $\sim 400 \mathrm{~W}$ (similarly as real $\left.Q_{-} V E N T\right)$. It means that amount of heating power was adequate, but the distribution of heating power should be improved.

The most demanding parts for increase of heating were right legs and arms, especially right lower arm. The slightly cool sensations on these parts were caused by the effect of radiation from side windows, which were very cold. This effect was minimalized by climate control which distributed substantial part of energy to the feet and side vents, but still remained apparent and measureable by thermal manikin.

\section{Discussion}

The comfort zones method was adopted to evaluate thermal comfort by using thermal manikin Newton. By this method is possible to analyse local thermal comfort, which allows to make recommendation about distribution and directioning of air flow from vents. Results of human subjects proved that the method is reliable in both summer and winter conditions

Based on the VTSCC simulation is possible to recommend how many power is necessary to deliver into the cabin to reach an optimal comfort temperature inside a cabin. The VTSCC model was designed as 3-airzone model. However, only 1-airzone configuration was used for calculations in this study to simplify input data file. We incline to an opinion that for such kind of models as VTSCC, it is better to keep versatility of the model. It means to use simple model for different type of cars instead of more complex and detailed model valid only for one specific car. Which would require additional input data to define advection scheme of multi-airzone model and other localized parameters. The more detailed studies are better to carry out using the CFD (Computational Fluid Dynamics) simulations [14].

Despite the simplicity of the model we can obtain interesting information about the HVAC power needs to improve thermal comfort. The model also allows to considered effect of RH, however in this study the RH of feeding air was not measured.

In this moment only the total energy needed to provide thermal comfort temperature was considered. The next step would be the algorithm solving the problem how to prepare the ventilation air to provide optimal conditions.

\section{Conclusion}

The evaluation of thermal comfort using thermal manikin was verified. The information about the local thermal comfort by the simulator was relevant and helpful to investigate car cabin environment. In addition, the simulation of heat loads was performed to reveal energy demand to improve thermal comfort in car cabin

In this moment, the testing of real-time conditions and the real-time recommendation based on the CAN data provided by the car is under development.

\section{Acknowledgement}

The research was supported by the project LO1202 Netme Centre Plus with the financial support from the Ministry of Education, Youth and Sports of the Czech Republic under the "National Sustainability Programme I" and the project of the Josef Božek Competence Centre for Automotive Industry TE01020020.

\section{References}

1. E. Foda, Evaluating local and overall thermal comfort in buildings using thermal manikins (Phd Thesis, Aalto University, 2012)

2. M. Fojtlín, J. Fišer, J. Pokorný, A. Povalač, T. Urbanec, M. Jícha, Journal of Thermal Biology, 69 (2017)

3. ISO 14505-2, Ergonomics of the thermal environment: Evaluation of thermal environments in vehicles: Part 2: Determination of equivalent temperature (ISO standard, 2006)

4. T. Kiss, L. Chaney, J. Meyer, SAE Int. J. Passeng. Cars - Mech. Syst., 6, 15 (2013)

5. M. Fayazbakhsh, M. Bahrami, SAE Technical Paper, 14 (2013)

6. D. Marcos, F. J. Pino, C. Bordons, J. Guerra, Appl. Therm. Eng., 66, 11 (2014)

7. B. Torregrosa-Jaime, F. Bjurling, J. M. Corberán, F. Di Sciullo, J. Payá, Appl. Therm. Eng., 75, 9 (2015)

8. H. Lee, Y. Hwang, I. Song, K. Jang, Energy, 90, 10 (2015)

9. F. Brèque, M. Nemer, 12th international Modelica Conference (2017)

10. J. Pokorný, J. Fišer, M. Jícha. In Proceedings of Ambience14\& 10i3m, 6 (Tampere, 2014)

11. J. Pokorný, J. Fišer, M. Jícha, Advances In Engineering Software, 76, 8 (2014)

12. J. Pokorný, J. Fišer, M. Fojtlín, M. Jícha, Simulace budov a techniky prostředí (2016)

13. D.P. Wyon, S. Larsson, B. Forsgren, and I. Lundgren, SAE Technical Paper 890049, 11 (1989)

14. R. Ambs, SAE Technical Paper, 10 (2002) 